Article

\title{
Improvement of Sensorial, Physicochemical, Microbiological, Nutritional and Fatty Acid Attributes and Shelf Life Extension of Hot Smoked Half-Dried Pacific Saury (Cololabis saira)
}

\author{
Md. Abdul Baten 1,+, Na Eun Won ${ }^{2,+}$, Jae Hak Sohn ${ }^{2,3}$, Jin-Soo Kim ${ }^{4}$, Md. Mohibbullah 1,*(D) \\ and Jae-Suk Choi $2,3, *$ (D) \\ 1 Department of Fishing and Post Harvest Technology, Sher-e-Bangla Agricultural University, \\ Dhaka 1207, Bangladesh; mabaten.fpht@sau.edu.bd \\ 2 Seafood Research Center, Silla University, \#605, Advanced Seafood Processing Complex, Wonyang-ro, \\ Amnam-dong, Seo-gu, Busan 49277, Korea; ftrnd2@silla.ac.kr (N.E.W.); jhsohn@silla.ac.kr (J.H.S.) \\ 3 Department of Food Biotechnology, Division of Bioindustry, College of Medical and Life Sciences, \\ Silla University, Busan 46958, Korea \\ 4 Department of Seafood and Aquaculture Science, Gyeongsang National University, \\ Tongyeong-si 53064, Korea; jinsukim@gnu.ac.kr \\ * Correspondence: mmohib.fpht@sau.edu.bd (M.M.); jsc1008@silla.ac.kr (J.-S.C.); \\ Tel.: +88-02-4481-4069 (M.M.); +82-51-248-7789 (J.-S.C.) \\ + The two authors contributed equally.
}

Received: 15 June 2020; Accepted: 24 July 2020; Published: 27 July 2020

\begin{abstract}
Half-dried Pacific saury of Cololabis saira (HDPS) is a fatty fish of high nutritional value with remarkable consumer interest in the Asia Pacific region, however, it undergoes various deteriorative changes associated with browning, bacterial contamination, oxidation, and decreased sensory attributes while marketed in various processed forms. To withstand these complications, research aimed to investigate the hot smoking technology to improve physicochemical, microbiological, and sensory attributes of HDPS with prolonged shelf life in storage conditions. The HDPS fillets were processed with hot smoking $\left(70^{\circ} \mathrm{C}\right)$ using various sawdust materials of Apple, Chestnut, Oak, Cherry, and Walnut, wherein the smoke time was set at different time points of 0, 20, 25, and $30 \mathrm{~min}$. The results indicated that $25 \mathrm{~min}$ of smoking time with the selective Oak sawdust showed better sensorial characteristics, physicochemical properties, and microbiological qualities. Moreover, HDPS possessed higher nutritional value and valuable functional fatty acids, particularly docosahexaenoic acid and eicosapentaenoic acid, having a storage ability of up to 30 days at $10^{\circ} \mathrm{C}$. The processed HDPS offered a reduced level of Trimethylamine-N-oxide and Benzo[a]pyrene contents, indicating the acceptable and safe for human consumption. Therefore, HDPS with hot smoking could likely be a promising technique for preserving the premium quality of the product by providing desired characteristics of health and nutrition to end-point consumers.
\end{abstract}

Keywords: hot smoking of fish; sensory evaluation; physicochemical properties; microbiology and nutrition

\section{Introduction}

Worldwide, fish are highly valuable and nutritious food items, and there is growing interest in fish consumption as they are high in protein with a plethora of omega- 3 and -6 polyunsaturated fatty acids, which are essential for human to maintain normal body functions [1]. Considering such various health facts of consuming fish and fish products, fish processors have been searching for a technique 
that is more effective than traditional ones, by which a fish with safety, nutrition, and delicacy of taste can be precisely ensured [2]. The Pacific saury, Cololabis saira (Brevoort, 1856), is a member of the family Scomberesocidae and is also known as mackerel pike or skipper [3]. It is a widely distributed fish species ranging from subarctic to subtropical regions throughout the Northwestern Pacific Ocean [4]. It is a highly migratory species and is mostly caught by countries such as Japan, China, Chinese Taipei, Russia, South Korea, and Vanuatu [5]. The Pacific saury is a commercially important fish species, especially in South Korea and traditionally known as Gwamegi in the Korean food industry [6]. This fish species is marketed in raw, frozen, and processed forms, including semi-dry, seasoned dry, and marinated products.

Smoking is a traditional fish preservation method, having remarkable economic importance worldwide [7], which is associated with combined treatment as followed by the salting, drying, and heat treatment [8]. Nowadays, smoked fish and fishery products have shown greater appeal to the consumer due to their delicacy in taste, aroma, and color [9]. Smoking treatment preserves food mainly because of the synergistic effects of temperature, table salt, and other chemical substances released from sawdust with a reduced water activity [10]. Moreover, smoking treatment prevents the growth of microbes and delays the oxidative changes in food materials [11]. The incomplete burning of wood or sawdust helps to release the volatile chemical compounds deposited on fish food surfaces, and, thereby, the process limits bacterial growth [12]. Smoking technology maintains good physicochemical characteristics of foods, such as $\mathrm{pH}$ level, volatile basic nitrogen (VBN) level, thiobarbituric acid reactive substances (TBARS) level, textural characteristics, and fatty acid profile and eventually improves sensory quality to the end-point consumer with extended shelf life [13]. Currently, the two types of smoking methods have been practiced for processing and preservation of fishery products; cold smoking $\left(30^{\circ} \mathrm{C}\right)$, smoking without thermal breakdown [14], and hot smoking $\left(70-80^{\circ} \mathrm{C}\right)$, with a thermal breakdown [15]. Among these, the hot smoked processing products are considered to be more acceptable by the consumer over cold-smoked ones, because of delicacy in color and attractive appearance [10].

Despite the popularity of using hot smoking in the preservation of fish and fishery products, the underlying mechanism of interactions between wood-derived chemicals and the food matrix which achieve its sensorial, physicochemical, microbiological, nutritional, and fatty acid profiling attributes is rudimentary. The hot smoke method has been employed for $70-80{ }^{\circ} \mathrm{C}$ heat treatment and results in the cooking of fish with considerable palatability, thus making it suitable for direct consumption [10]. The quality of smoked fishery product was assessed using (1) sensory evaluation based on color, texture, odor, flavor, and overall preference; (2) physicochemical parameters such as textural properties and levels of $\mathrm{pH}, \mathrm{VBN}$, TBARS, Trimethylamine-N-oxide (TMAO), and fatty acid profile; (3) nutritional value, including calories, protein, lipid, and minerals; and (4) microbial-growth estimation [16,17]. Although, there are a wide variety of studies that have examined the effect the hot smoking method has on the physicochemical composition of different fish species [7,18-21]. However, there has been no study yet performed on the effect of the hot smoking treatment in half-dried Pacific saury (HDPS). Therefore, the current study aimed to provide scientific rationality when choosing a hot smoking treatment to improve the sensory, physicochemical, microbiological, nutritional, and shelf life extension attributes of half-dried Pacific Saury (Cololabis saira).

\section{Materials and Methods}

\subsection{Collection and Preparation of Sample}

Half dried Pacific Saury (Cololabis saira) was collected from raw fish markets of South Korea, stored on ice flakes immediately after collection, and washed with tap water before filleting. The fish was filleted in lengthwise and any unwanted parts, such as scales and stomach remaining in the fillet, were carefully removed. The diameter was maintained as $14.7 \times 2.6 \times 0.3 \mathrm{~cm}$, of which, the average weight was $22.8 \pm 0.77 \mathrm{~g}$. Then, the prepared fish sample was divided into two groups such as raw and smoked samples. 


\subsection{Hot Smoking Treatment}

Smoking treatment is performed electronically and the temperature was fixed at $70{ }^{\circ} \mathrm{C}$ for different time-dependent treatment groups followed by $0,10,15,20,25$, and 30 min of smoking. The smoke generated from different smoking materials was of Apple, Oak, Chestnut, Walnut, and Cherry, and the procedures for the preparation of hot smoking HDPS were followed by our previous reports [16,17].

\subsection{Analysis of Sensorial Characteristics}

The sensory analysis was evaluated by recruiting the trained 10 panelists with ages between 25 and 40 , and the sensory parameters were considered to be the odor, color, flavor, and overall preference of raw and smoked HDPS products [16,17]. During this period, all of the experimental samples were unbiasedly encoded. Then, $10 \mathrm{~g}$ of the sample was given to each panelist and they were requested to score using a numerical number on a hedonic scale, where 1 stands for "extremely dislike" and 9 for "extremely like" [22].

\subsection{Analysis of Physical Properties}

The method of Goulas and Kontominas [14] was followed to determine the weight loss of the fish fillets.

The odor intensity of the processed HDPS fillet was determined at a different smoking time intervals. The $5 \mathrm{~g}$ sample was taken from different experimental groups, kept in a $50 \mathrm{~mL}$ conical tube, and covered with parafilm. Upon closing the lid, the odor intensity was measured instrumentally (XP-329, New Cosmos Electric Co. Ltd., Osaka, Japan) [23].

According to Mohibbullah et al. [16] and Chen et al. [24], the color of the surface of each HDPS sample was assessed numerically with an instrument of CM-700d, Konica Minolta (Tokyo, Japan).

The smoked sample from each group was taken for texture analysis using a Brookfield Texture Analyzer (Massachusetts, USA) and equipped with a software system connecting to the computer (Texture PRO CT, Middleboro, MA, USA). Data processing and collection were followed by the study of Ganesan \& Benjakul [25].

\subsection{Analysis of Biochemical Properties}

A serial dilution method was used to analyze the total bacterial count, where $9 \mathrm{~g}$ of sample was mixed with $45 \mathrm{~mL}$ sterile saline solution and homogenized. After that, the diluted samples $\left(10^{-1}, 10^{-2}\right.$, and $10^{-3}$ ) were spread, incubated, and counted the observed colony, following the report of Chen et al. [24]. The total coliform count of fish samples was estimated by following the methods of the US Food and Drug Administration (FDA). The positive results were considered as sadZ gas production observed in the EC culture medium.

A $2 \mathrm{~g}$ HDPS fillet sample from each treatment group was taken with $18 \mathrm{~mL}$ distilled water and mixed properly by using a Homogenizer (SHG-15D, SciLab, Seoul, Korea) for $3 \mathrm{~min}$. Then, the homogenate was collected for measuring pH using an Ohaus Starter $2100 \mathrm{pH}$ meter (Seoul, Korea).

The VBN value of smoked HDPS was estimated by using a Conway micro diffusion method [17].

According to the previous study of Oğuzhan Yildiz [26], a $5 \mathrm{~g}$ smoked HDPS sample was homogenized with a $12.5 \mathrm{~mL}$ TCA solution (20\% trichloroacetic acid in $2 \mathrm{M}$ phosphoric acid). The absorbance was measured at $530 \mathrm{~nm}$ wavelength using a microplate reader (SPECTROstar Nano, Newtown, UK). The lipid peroxidation values were expressed as $\mathrm{mg}$ of malonaldehyde per $\mathrm{kg}$ of processed HDPS fillet.

\subsection{Analysis of TMAO Level}

The TMAO content in both smoked and raw HDPS was quantitatively determined using a Gas Chromatography-Mass Spectrometry (GC/MS) analysis. The analysis method of TMAO content was followed by the previous study of Mohibbullah et al. [16]. The TMAO content of raw and smoked HDPS was identified and quantified by comparing it with the standard compound (Sigma-Aldrich, St. Louise, MO, USA). 


\subsection{Analysis of Nutritional Composition}

To quantify the nutritional quality of hot smoked HDPS fillet, the standard method of AOAC [27] was followed and performed at the Traditional Microorganism Resources Center, Keimyung University, Daegu, Korea.

\subsection{Analysis of Fatty Acids}

Gas chromatography (Shimadzu Corp., Kyoto, Japan) with a flame ionization detector (GC-FID) was used for the quantification of fatty acid methyl esters (FAMEs). Supelco SP-2560 column (100 m $\times$ $0.25 \mathrm{~mm} \times 0.25 \mu \mathrm{m}$ ) with an oven temperature of $240{ }^{\circ} \mathrm{C}$, which increased from $100^{\circ} \mathrm{C}$ to $200{ }^{\circ} \mathrm{C}$ at a flow rate of $3.5^{\circ} \mathrm{C} / \mathrm{min}$, was used for the separation of FAMEs from fish fillets. The helium gas was used as a carrier at a split ratio of 1:50, and the obtained FAME signals were analyzed and validated by comparing the retention time of standard fatty acids [12].

\subsection{Analysis of Benzo[a]pyrene (BaP)}

The Bap content was analyzed using a High-Performance Liquid Chromatography (HPLC; LC-20A, Shimadzu Corp.), with a fluorescence detector (RF-20A, Shimadzu Corp.) of excitation and an emission wavelength of $294 \mathrm{~nm}$ and $404 \mathrm{~nm}$, respectively, according to the instruction of the Ministry of Food and Drug Safety (MFDS) [28] and performed at Hankyul Institute of Technology Analysis (Sacheon-si, Gyeongsangnam-do, South Korea).

\subsection{Statistical Analysis}

All of the experimental results were expressed as the mean \pm standard deviation (std). The statistical analysis was performed using an IBM SPSS software version 20.0 (IBM, Corp., New York, USA), followed by one-way analysis of variance (ANOVA) with LSD and Duncan's multiple range tests. The statistical significance in the analysis was deemed at $p<0.05$.

\section{Results}

\subsection{Effect of Hot Smoking with Different Sawdust Materials on Odor Intensity and Sensory Characterization}

The sawdust materials help to develop the color and flavor of the HDPS smoked product. Instrumental odor intensity was observed and found to be significantly higher $(p<0.001)$ while using Oak sawdust-smoke followed by cherry, walnut, and apple sawdust-smoke at two different smoking times of 20 and $25 \mathrm{~min}$ (Figure 1a). The results of overall preferences while using different sawdust materials were significantly $(p<0.001)$ increased, except for chestnut, as compared with raw HDPS (Figure 1b). The results suggested that Oak sawdust was found to be the most appropriate smoking material for developing sensory quality in HDPS.
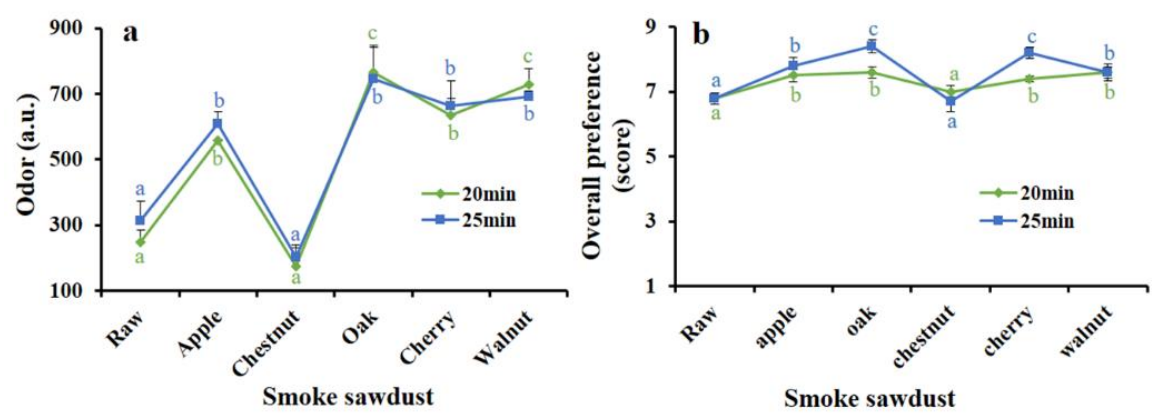

Figure 1. Use of different sawdust materials on the improvement of sensory attributes of (a) odor (a.u.) and (b) overall preference (hedonic score) at 20 and 25 min of hot smoking times of half-dried Pacific Saury (HDPS). Data represent the mean \pm std of 10 observations, where groups not sharing a letter are expressed as significantly different $(p<0.05)$. 


\subsection{Optimization of Smoking Treatment}

The instrumental odor intensity was found to be significantly $(p<0.001)$ higher with the increase in smoking time (Figure 2a). The optimum smoke time was perceived by evaluating the hedonic scale $(0-9)$ based on sensory analysis of smoked HDPS. We found that smoking times of 20 and $25 \mathrm{~min}$ increased sensory attributes (appearance, odor, taste, and overall preference) significantly $(p<0.01$ and/or $p<0.001$ ) (Figure $2 b$ ). For further validation, we considered whether those smoking times could maintain proper physicochemical properties in HDPS, and, therefore, we kept continuing hot smoking treatment time-dependently for further experiments.
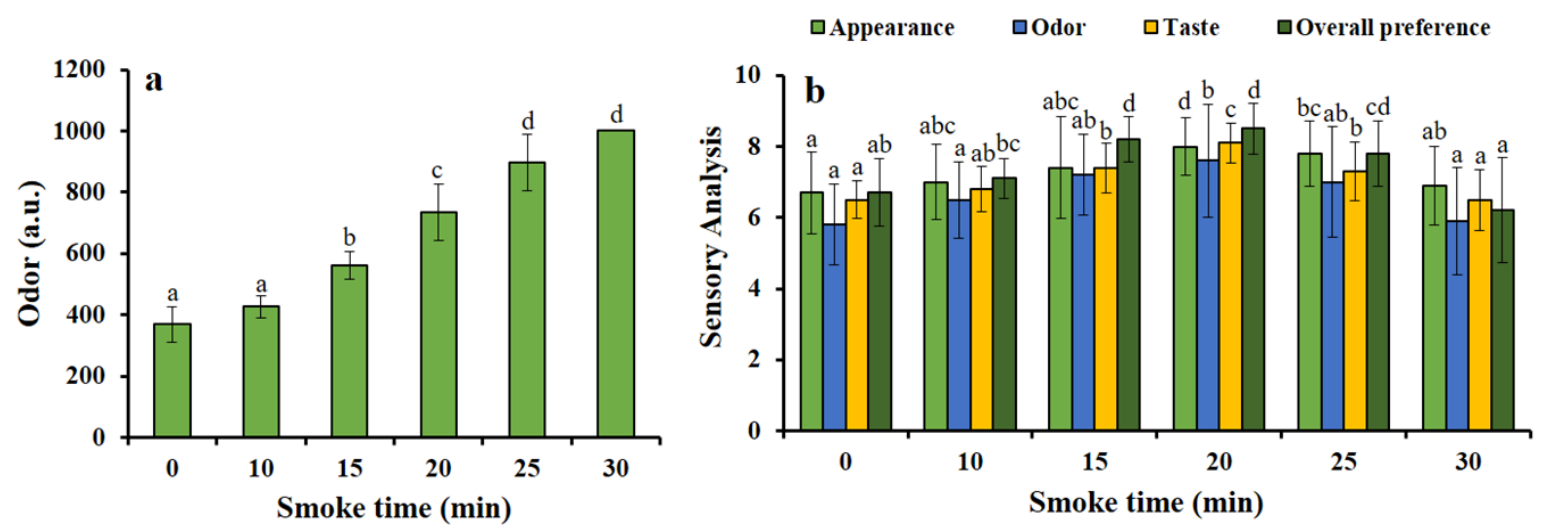

Figure 2. Different smoking times on the changes of (a) odor (a.u.) and (b) sensory quality attributes of hot smoked HDPS. Data represent the mean \pm std of 10 observations, where groups not sharing a letter are expressed as significantly different $(p<0.05)$.

\subsection{Hot Smoking Treatment Improved Physical Properties of HDPS}

\subsubsection{Changes of Weight Loss by the Smoking Time}

The weight loss of a fish product indicates the removal of moisture from the fish, which is ultimately responsible for reducing the firmness of fish products. A non-significant difference was found in the weight loss analysis of hot smoked HDPS groups of different smoking times (Figure 3a).

\subsubsection{Changes of Instrumental Texture Analysis by Smoking Time}

Textural properties of hot smoked HDPS product were analyzed instrumentally and the increase in hardness between 25 and 30 min smoking time was found to be significant $(p<0.05$ and $p<0.001)$, and other textural parameters such as Chewiness, Springiness, and Cohesiveness remained the same and non-significant along with the increased smoking time (Figure $3 b$ ).

\subsubsection{Changes of Odor Intensity by the Smoking Time}

Odor intensity is considered as a critical parameter for increasing the acceptability of fishery products to the consumer. In this study, odor intensity was calculated at 5 and $10 \mathrm{~min}$ intervals at different smoking periods of $0,20,25,30 \mathrm{~min}$. The study found odor intensity increased with increasing smoke time and was significantly higher $(p<0.01)$ at 30 min of smoking time (Figure $3 c$ ).

\subsubsection{Changes of Color Value by the Smoking Time}

The color of fish products is one of the important attributes to positively attract consumer preference. The color value (lightness, redness, and yellowness) of HDPS fillet remained constant, indicating that the hot smoke had no negative influence on HDPS fillet (Figure 3d). 

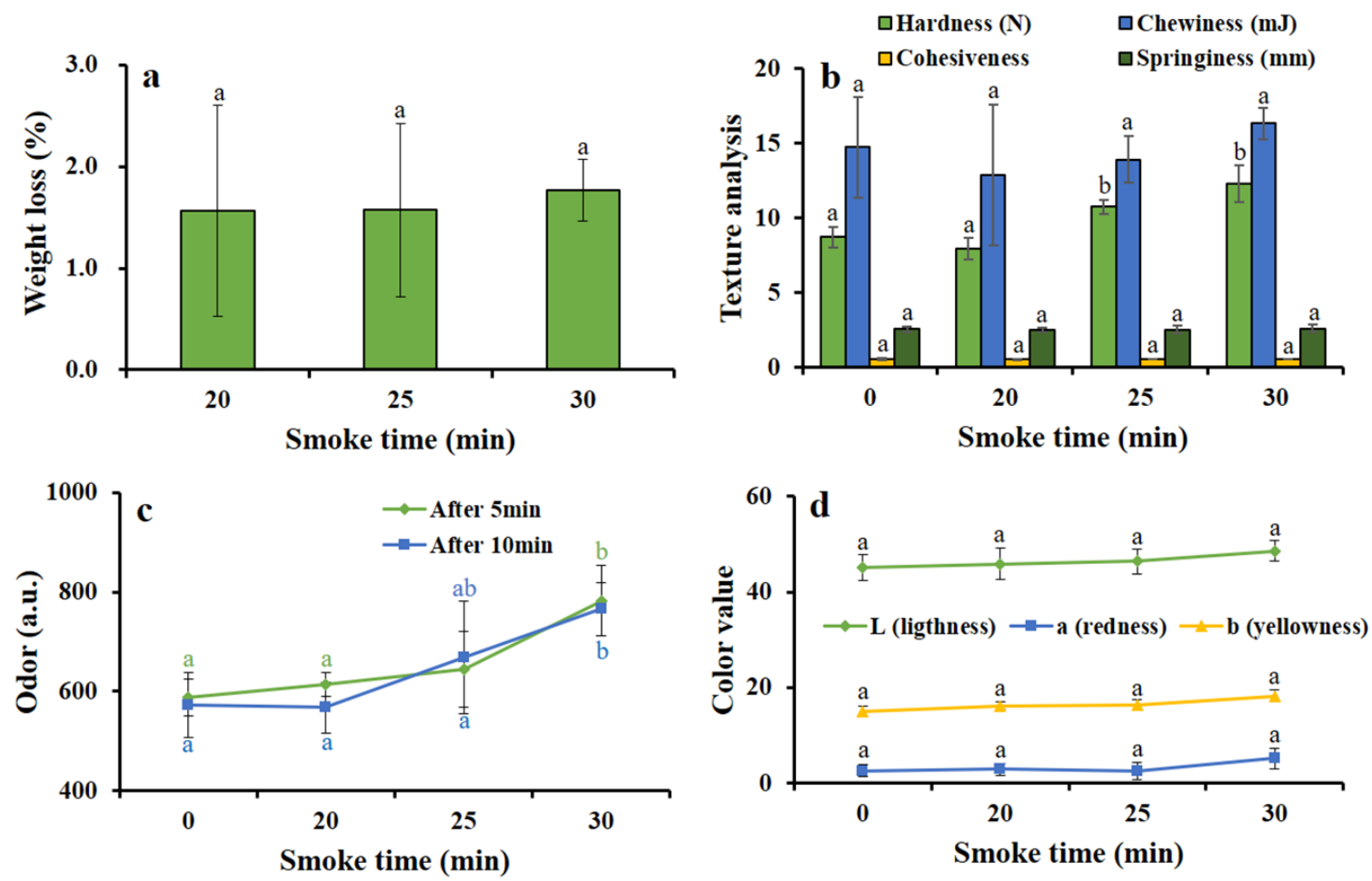

Figure 3. Different smoking times on the effects of (a) weight loss, (b) texture analysis, (c) odor (a.u.), and (d) color value of hot smoked HDPS. Data represent the mean \pm std of 10 observations, where groups not sharing a letter are expressed as significantly different $(p<0.05)$.

\subsection{Hot Smoking Treatment Improved Biochemical Features of HDPS}

\subsubsection{Changes of TBC by the Smoking Time}

The bacterial biomass is responsible for the spoilage of fish products. Smoking treatment with wood-smoke has antibacterial agents that could effectively suppress bacterial growth. The study found the total bacterial count was significantly $(p<0.01$ and $p<0.001)$ decreased while increasing the smoke time of 20, 25, and $30 \mathrm{~min}$ (Figure 4a).

\subsubsection{Changes of $\mathrm{pH}$ Value by the Smoking Time}

The fish product quality depends on the $\mathrm{pH}$ value. We found that the $\mathrm{pH}$ value significantly $(p<0.05)$ decreased with increased smoke time (Figure $4 b)$.

\subsubsection{Changes of TBARS Value by the Smoking Time}

The TBARS value indicates the degradation of fat in smoked HDPS products. The value of TBARS non-significantly increased up to the smoke time of $20 \mathrm{~min}$, and afterward, it gradually decreased because of increasing the smoke time (Figure 4c).

\subsubsection{Changes of VBN Value by the Smoking Time}

The VBN value is used as an indicator for the evaluation of the degree of spoilage in fish and fishery products. In Figure 4d, initially, the VBN value at 20 min smoking time increased non-significantly, while that of 25 and 30 min of smoking treatment decreased the VBN value significantly $(p<0.001)$.

\subsubsection{Changes of Sensorial Characteristics by the Smoking Time}

The sensory evaluation was performed by well-trained panelists. The sensory characteristics of appearance, odor, taste, and overall preference were significantly $(p<0.001)$ increased at the smoke 
times of 20, 25, and $30 \mathrm{~min}$ (Figure 4e). Among the smoke time, better sensory scores were observed at 25 min of smoking time. Therefore, we optimized and chose, based on the time-dependent results, this 25-min smoking time for further experiments.
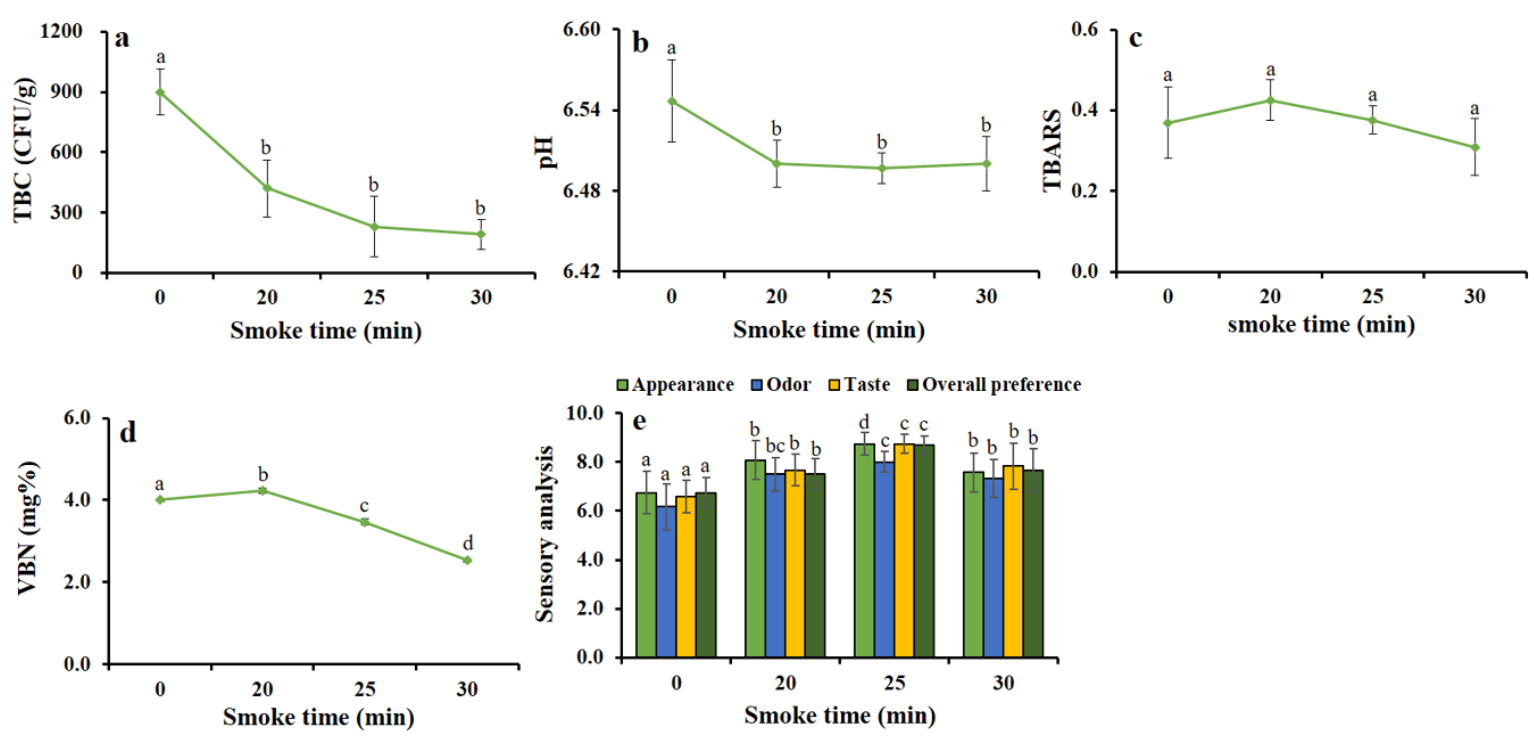

Figure 4. Different smoking times on the improvement of (a) TBC (CFU/g), (b) pH, (c) TBARS, (d) VBN $(\mathrm{mg} \%)$, and (e) sensory evaluation of hot smoked HDPS. Data represent the mean \pm std of 10 observations, where groups not sharing a letter are expressed as significantly different $(p<0.05)$.

\subsection{Hot Smoking Preserved Biochemical Characteristics of HDPS during Storage Condition}

\subsubsection{Changes of Microbiological Activity}

Temperature is an important determinant for bacterial growth promotion in fishery products during storage period. The hot smoked HDPS fillet was kept at two different temperatures $\left(10^{\circ} \mathrm{C}\right.$ and $15^{\circ} \mathrm{C}$ ) for 0 to 32 days. Bacterial growth was not observed at a storage temperature of $10^{\circ} \mathrm{C}$, but at $15^{\circ} \mathrm{C}$ temperature, bacterial growth appeared after 18 days of storage period (Table 1). Moreover, the coliform count was found absent in both storage temperatures. The results of microbial growth indicate that hot smoking with Oak sawdust might have the potential to suppress bacterial growth most effectively at a storage temperature of $10^{\circ} \mathrm{C}$, and, thereby, it amazingly extended the shelf life of the HDPS product up to 32 days.

Table 1. Microbial activity of hot smoked HDPS during storage period.

\begin{tabular}{ccccc}
\hline \multirow{2}{*}{ Storage Duration (Days) } & \multicolumn{2}{c}{ Bacteria (CFU/g) } & \multicolumn{2}{c}{ Coliform } \\
\cline { 2 - 5 } & $\mathbf{1 0}{ }^{\circ} \mathbf{C}$ & $\mathbf{1 5}{ }^{\circ} \mathbf{C}$ & $\mathbf{1 0}^{\circ} \mathbf{C}$ & $\mathbf{1 5}^{\circ} \mathbf{C}$ \\
\hline 0 & 0 & 0 & 0 & 0 \\
3 & 0 & 0 & 0 & 0 \\
10 & 0 & 0 & 0 & 0 \\
14 & 0 & 0 & 0 & 0 \\
18 & 0 & 21.67 & 0 & 0 \\
21 & 0 & 36.67 & 0 & 0 \\
24 & 0 & 45.00 & 0 & 0 \\
27 & 0 & - & 0 & - \\
30 & 0 & - & 0 & - \\
32 & 0 & - & 0 & - \\
\hline
\end{tabular}




\subsubsection{Changes of VBN Level}

The VBN value of smoked HDPS was determined intermittently in two storage temperatures at $10^{\circ} \mathrm{C}$ and $15{ }^{\circ} \mathrm{C}$ from 0 to 32 days. The VBN value was found to have a significantly $(p<0.001)$ increasing trend and values ranging between 4.5 and $23.3(\mathrm{mg} \%)$, and 4.5 and $25.0(\mathrm{mg} \%)$ at $10{ }^{\circ} \mathrm{C}$ and $15^{\circ} \mathrm{C}$ storage temperatures, respectively (Figure 5 a).
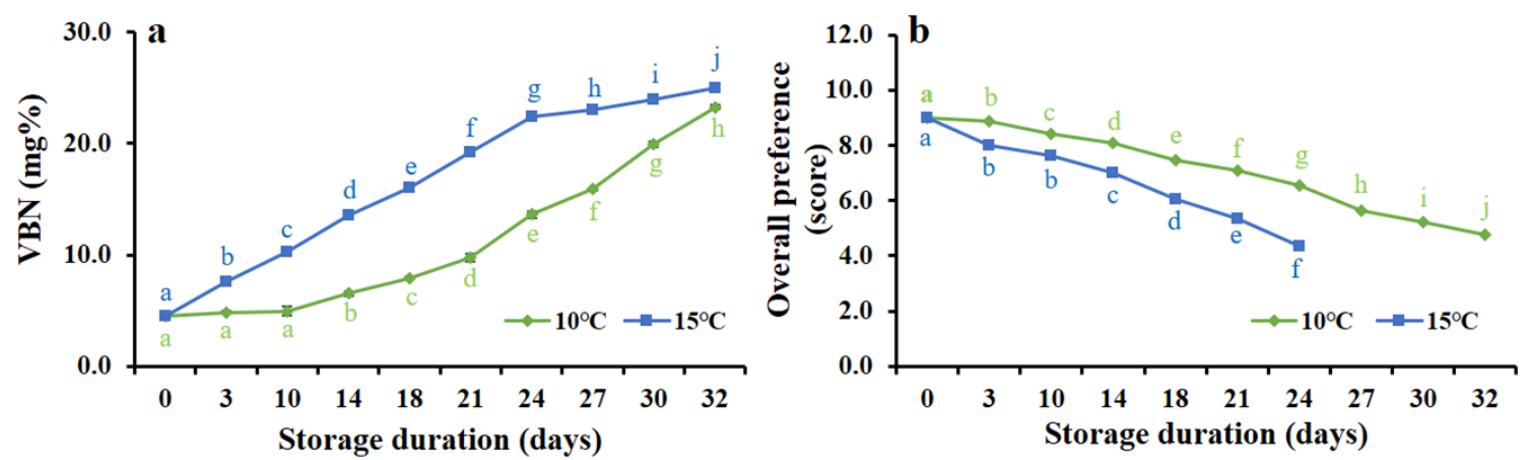

Figure 5. Consequences of storage time on (a) volatile basic nitrogen (VBN) and (b) sensory evaluation (overall preference) of hot smoked HDPS at two different storage temperature of $10{ }^{\circ} \mathrm{C}$ and $15{ }^{\circ} \mathrm{C}$ Data represent the mean \pm std of 10 observations, where groups not sharing a letter is expressed as significantly different $(p<0.05)$.

\subsubsection{Changes of Overall Preferences}

The sensory evaluation (overall preference) of hot smoked HDPS was found to have significantly $(p<0.001)$ declined with the extension of storage time at two different storage conditions of $10^{\circ} \mathrm{C}$ and $15^{\circ} \mathrm{C}$ (Figure $5 \mathrm{~b}$ ). The results indicate that the overall preference remained acceptable even after 30 days of storage time at $10{ }^{\circ} \mathrm{C}$, and on the other hand, at $15{ }^{\circ} \mathrm{C}$ storage product remained safe up to 21 days and then decreased its sensorial attributes. The study reveals that hot smoked HDPS at $10^{\circ} \mathrm{C}$ storage temperature provided better product quality in extending the storage duration.

\subsection{Hot Smoking Restricted TMAO Level}

The TMAO concentration is one of the predominant factors for decreasing the freshness of fishery products, when it introduces, which undergoes an off-odor of the product, and therefore, it is considered as a key determinant for the degree of spoilage. Here, we determined whether the TMAO level had been suppressed using a selective Oak sawdust-mediated hot smoking of HDPS. The TMAO was identified and quantified by injecting the reference TMAO reagent into the GC/MS. The resultant peak area appeared at the same retention time of $1 \mathrm{~min} 25 \mathrm{~s}$ among different treatment groups (Figure 6). Following the results of TMAO content by GC/MS analysis, hot smoked HDPS contained a low level of TMAO which was $1.13 \pm 0.17 \mu \mathrm{g} / 100 \mathrm{~g}$, while raw HDPS was $2.16 \pm 0.28 \mu \mathrm{g} / 100 \mathrm{~g}$ (triplicate measurement), indicating that hot smoking with Oak sawdust had a suppressive effect on TMAO production in HDPS.

\subsection{Hot Smoking Preserved Nutritional Quality}

The nutritional value of smoked fish and fishery products may vary upon changing of handling, processing, and storage conditions. In analyzing the nutritional quality of hot smoked HDPS fillet, the total calories were $479.885 \mathrm{kcal} / 100 \mathrm{~g}$, in which the major components such as carbohydrates, lipids, (crude, trans and saturated fat) and proteins (crude) were $0.316,46.897$, and $34.720 \mathrm{~g} / 100 \mathrm{~g}$, respectively, (Table 2). Hot smoked HDPS possessed higher mineral contents sodium $(208.829 \mathrm{mg} / 100 \mathrm{~g})$, potassium (369.862 mg/100 g), calcium (60.013 mg/100 g), and iron (2.05 mg/100 g). 

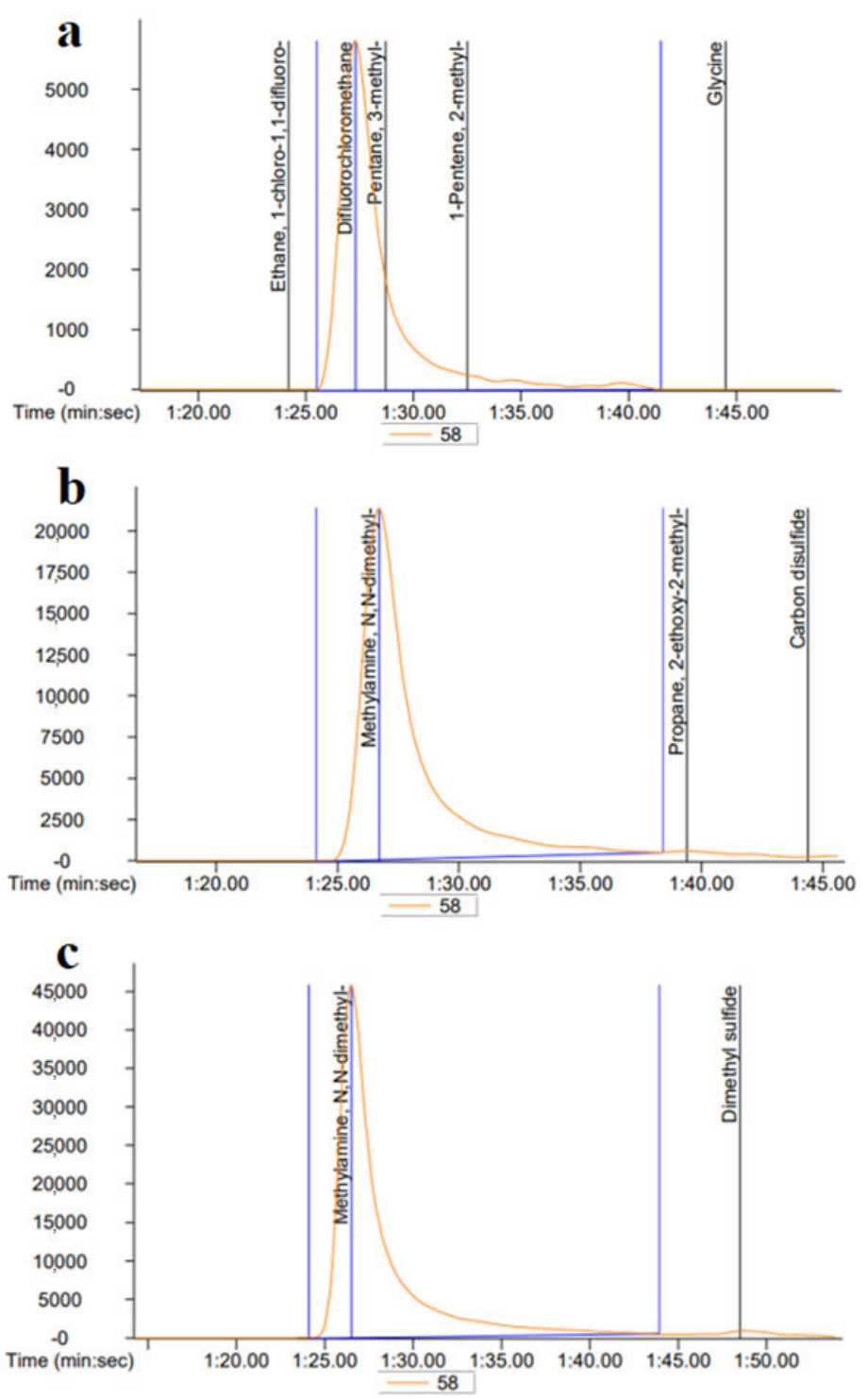

Figure 6. The trimethyl N-oxide (TMAO) was identified and quantified by GC/MS analysis. The representative chromatograms of (a) standard TMAO, (b) raw HDPS, and (c) hot smoked HDPS. The TMAO was identified and quantified by the reference TMAO injecting into the GC/MS. The TMAO spikes in the chromatograms appeared at $1 \mathrm{~min} 25 \mathrm{~s}$ of retention time among different treatment groups.

Table 2. Nutritional composition of hot smoked HDPS.

\begin{tabular}{ccc}
\hline Test Items & Unit & Test Results \\
\hline Calories & $\mathrm{kcal} / 100 \mathrm{~g}$ & 479.885 \\
Sodium & $\mathrm{mg} / 100 \mathrm{~g}$ & 208.829 \\
Carbohydrate & $\mathrm{g} / 100 \mathrm{~g}$ & 0.316 \\
Sugars & $\mathrm{g} / 100 \mathrm{~g}$ & 0.181 \\
Crude fat & $\mathrm{g} / 100 \mathrm{~g}$ & 37.749 \\
Trans fat & $\mathrm{g} / 100 \mathrm{~g}$ & 0.131 \\
Saturated fat & $\mathrm{g} / 100 \mathrm{~g}$ & 9.017 \\
Cholesterol & $\mathrm{mg} / 100 \mathrm{~g}$ & 51.588 \\
Crude protein & $\mathrm{g} / 100 \mathrm{~g}$ & 34.720 \\
Potassium & $\mathrm{mg} / 100 \mathrm{~g}$ & 369.862 \\
Calcium & $\mathrm{mg} / 100 \mathrm{~g}$ & 60.013 \\
Iron & $\mathrm{mg} / 100 \mathrm{~g}$ & 2.050 \\
Vitamin D & $\mathrm{mg} / 100 \mathrm{~g}$ & $\mathrm{ND}$
\end{tabular}




\subsection{Hot Smoking Preserved Beneficial Fatty Acids}

We identified and quantitated the fatty acids from hot smoked HDPS products and precisely elucidated on its positive correlation between hot smoking process, and its valuable and functional fatty acid contents. We, therefore, found 36 fatty acids in hot smoked HDPS and compiled them into three groups as monounsaturated fatty acids (MUFAs), polyunsaturated fatty acids (PUFAs), and saturated fatty acids (SFA). Among them, the contents of MUFAs, PUFAs, and SFA were $6.37 \mathrm{~g} / 100 \mathrm{~g}, 5.89 \mathrm{~g} / 100 \mathrm{~g}$, and $4.36 \mathrm{~g} / 100 \mathrm{~g}$, respectively (Table 3 ). Of 36 fatty acids in HDPS identified and quantified, the lead fatty acid was found to be docosahexaenoic acid (DHA; $3.03 \mathrm{~g} / 100 \mathrm{~g}$ ) followed by erucic acid ( $2.79 \mathrm{~g} / 100 \mathrm{~g}$ ), cis-11-eicosenoic acid (1.81 g/100 g), eicosapentaenoic acid (EPA; $1.17 \mathrm{~g} / 100 \mathrm{~g})$, and oleic acid (OLA; $1.04 \mathrm{~g} / 100 \mathrm{~g}$ ). In addition, HDPS with hot smoking contained a higher level of omega-3 (DHA and EPA) fatty acids, which are attributable to the beneficial health effects on humans.

Table 3. Fatty acid profile of hot smoked HDPS.

\begin{tabular}{|c|c|c|}
\hline \multicolumn{2}{|l|}{ Fatty Acids } & \multirow{2}{*}{$\begin{array}{c}\text { Hot Smoked HDPS }(\mathrm{g} / \mathbf{1 0 0} \mathrm{g}) \\
0.00\end{array}$} \\
\hline Butyric acid & C4: 0 & \\
\hline Caproic acid & C6: 0 & 0.00 \\
\hline Caprylic acid & C8: 0 & 0.00 \\
\hline Capric acid & C10: 0 & 0.00 \\
\hline Lauric acid & C12: 0 & 0.01 \\
\hline Tridecanoic acid & C13: 0 & 0.01 \\
\hline Myristic acid & C14: 0 & 1.17 \\
\hline Pentadecanoic acid & C15: 0 & 0.10 \\
\hline Palmitic acid & C16: 0 & 2.35 \\
\hline Stearic acid & C18: 0 & 0.43 \\
\hline Margaric acid & C17: 0 & 0.20 \\
\hline Heneicosanoic acid & C21: 0 & 0.00 \\
\hline Behenic acid & C22: 0 & 0.01 \\
\hline Arachidic acid & C20: 0 & 0.08 \\
\hline Tricosanoic acid & C23: 0 & 0.00 \\
\hline Lignoceric acid & C24: 0 & 0.00 \\
\hline \multicolumn{2}{|l|}{$\sum$ SFA } & 4.36 \\
\hline Myristoleic acid & C14: 1 & 0.01 \\
\hline Pentadecenoic acid & C15: 1 & 0.00 \\
\hline Palmitoleic acid & C16: 1 & 0.55 \\
\hline Margaroleic acid & C17: 1 & 0.00 \\
\hline Elaidic acid & C18: $1 \mathrm{n}-9 \mathrm{t}$ & 0.03 \\
\hline Oleic acid & C18: $1 \mathrm{n}-9 \mathrm{c}$ & 1.04 \\
\hline Cis-11-Eicosenoic acid & C20: $1 \mathrm{n}-9$ & 1.81 \\
\hline Erucic acid & $\mathrm{C} 22: 1 \mathrm{n}-9$ & 2.76 \\
\hline Nervonic acid & C24: $1 \mathrm{n}-9$ & 0.17 \\
\hline \multicolumn{2}{|l|}{$\sum$ MUFA } & 6.37 \\
\hline Linolelaidic acid & C18: 2 n-6t & 0.19 \\
\hline Linoleic acid & C18: $2 n-6 c$ & 0.32 \\
\hline$\curlyvee$-Linolenic acid & C18: $3 n-6$ & 0.02 \\
\hline Cis-11, 14-Eicosenoic acid & C20: $2 \mathrm{n}-6$ & 0.62 \\
\hline Docosadienoic acid & C22: $2 \mathrm{n}-6$ & 0.13 \\
\hline Cis-11, 14, 17-Eicosenoic acid & C20: $3 n-3$ & 0.07 \\
\hline$\alpha$-Linolenic acid & C18: $3 n-3$ & 0.23 \\
\hline Dihomo $\Upsilon$-Linolenic acid & C20: $3 n-6$ & 0.03 \\
\hline Arachidonic acid & C20: $4 \mathrm{n}-6$ & 0.08 \\
\hline Eicosapentaenoic acid & C20: $5 n-3$ & 1.17 \\
\hline Docosahexaenoic acid & $\mathrm{C} 22: 6 \mathrm{n}-3$ & 3.03 \\
\hline$\sum$ PUFA & & 5.89 \\
\hline
\end{tabular}

SFA: Saturated Fatty Acid; MUFA: Mono Unsaturated Fatty Acid; PUFA: Poly Unsaturated Fatty Acid. 


\subsection{Hot Smoking Restricted BaP Content}

In polycyclic aromatic hydrocarbons (PAHs), the $\mathrm{BaP}$ is one of the most promising organic compounds involved in the mutagenic or carcinogenic processes, and is released from wood materials whenever hot smoking is performed. We determined whether Oak sawdust-mediated hot smoking of HDPS possessed a BaP compound. The result obtained from HPLC analysis was marked as no detection of $\mathrm{BaP}$ compounds while injecting the samples with reference $\mathrm{BaP}$ at standard dilution conditions. Since the limit of quantification of BaP was $0.9 \mu \mathrm{g} / \mathrm{kg}$, the following injecting condition also did not allow for the quantification of the sample. It suggested that the content of $\mathrm{BaP}$ in hot smoked HDPS was shown to be acceptable and safe for human consumption.

\section{Discussions}

Fish and fishery products have been associated with a healthy balanced diet because of their variety of valuable nutrients, including protein, lipid, and especially, long-chain omega- 3 and -6 polyunsaturated fatty acids (n-3 and -6 PUFAs), as well as vitamins (e.g., A, D and B) and other minerals (e.g., iodine, selenium) [29]. Fish is a highly perishable food items because it contains a high concentration of unsaturated fatty acids, which initially are attacked by the oxygen, as a result, it gives rise to rancidity with off-odor, especially observed in smoked and dried fish, decreasing the shelf life by allowing collectively implicated enzymatic and bacterial actions to trigger various chemical changes in texture, appearance, taste, and overall qualities [30]. The present study was aimed at investigating development of a hot smoking method as an effective processing and preservation tool to improve the sensorial characteristics, physicochemical properties, and subsequent extension of the shelf life of HDPS, having a quality of improving health functions to the end-point consumers.

One of the easiest and simplest methods for evaluating the consumer products is sensory evaluation, which is associated with various sensorial parameters such as color, odor, taste, and overall preference; the scores of each attribute are based on a 9-point hedonic scale [22]. In the present study, when different sawdust materials (apple, oak, cherry, chestnut, and walnut) were used in hot smoking $\left(70{ }^{\circ} \mathrm{C}\right)$ process of HDPS fillet, time-dependently ranging from 0 to $30 \mathrm{~min}$ of smoking time, the study found highly acceptable sensory characteristics at a 25-min smoke time. In compliance with this result, significant sensory impacts were observed when hot smoking was performed with Wels catfish [31]. It is evident that sawdust material released several volatile compounds while smoking, among which phenols are likely to be the compounds predominantly responsible for developing color and aroma of food items [32]. The results obtained, the Oak sawdust material possessed the best sensory quality in HDPS, which is similar to the study of Mohibbullah et al. [16].

The firmness of fish products is one of the most significant quality parameters pertinent to consumer preference [33]. The processed HDPS remained unchanged in weight loss determination at a different smoke time $(20,25$, and 30$)$, indicating good quality smoked products for consumers. The texture profile of a seafood product is one of the most significant physical quality attributes, to which, a consumer can easily perceive to evaluate the hardness, springiness, adhesiveness, and gumminess of a given food [12]. In HDPS, all textural characters remained stable and considerable at different smoking times. The study showed that texture profile persisted steadily at the different smoke times $(0,20,25$, and $30 \mathrm{~min})$, which was more or less similar to the previous study by Mohibbullah et al. [16], who found springiness, cohesiveness, and hardness remained stable, but only chewiness increased far less after $15 \mathrm{~min}$ of smoking time. The odor intensity and color value play a significant role in the acceptance or rejection of fish products by the consumer [34]. The instrumental odor and color value remained unchanged for a smoke time of $25 \mathrm{~min}$, and the results corresponded to the previous report of Zzaman et al. [35].

It is evident that hot smoking treatment inhibits the growth of microorganisms [11], and in line with the present study, which suggested that a significant $(p<0.001)$ decrease in bacterial growth was found when the hot smoking time was $25 \mathrm{~min}$, it is likely that volatile materials existed in the wood smoke $[14,36]$. Positive and favorable consequences were observed in hot smoked HDPS; desirable 
and considerable levels of $\mathrm{pH}$, TBARS, and VBN were found at 25 min of smoking time, in comparison with other studies, which found the similar effects $[3,16,17,26]$. In storage conditions at $10{ }^{\circ} \mathrm{C}$ and $15^{\circ} \mathrm{C}$, the VBN value was found an increasing trend, but within an acceptable limit, which was similar to the reports of previous studies $[16,26,37]$. In addition, the overall sensorial impact of HDPS was significantly decreased with increasing storage time, however, $10^{\circ} \mathrm{C}$ storage conditions showed a better acceptance by panelists even after 30 days but $15^{\circ} \mathrm{C}$ did not. The bacterial growth on hot smoked HDPS (TBC and coliform) was not seen at $10^{\circ} \mathrm{C}$ after a period of 32 days of storage. It was reported that a combined treatment of superheated steam and smoking on squid showed preventive effects against microbial growth while storing at $10^{\circ} \mathrm{C}$ [12].

Conversion of TMAO into TMA (Trimethylamine) in fish after death usually happens due to the existing enzymes and bacterial action [17], and its quantification is an approach of evaluating fish and fishery product quality with a maximum allowable limit as $<10-15 \mathrm{mg} / 100 \mathrm{~g}[34,38]$. By applying hot smoke with Oak sawdust in HDPS, the TMAO content was significantly reduced when compared with raw HDPS, a similar effect as seen by the previous report [16,17]. Moreover, the nutritional composition of hot smoked HDPS remained high after treatment, indicating that there was less possibility of nutritional degradation during the treatment when compared with previous literature [38]. One of the salient features of using hot smoking with Oak sawdust was that HDPS possessed higher concentrations of fatty acids including MUFAs and PUFAs. Fatty acid is an important nutritional component that provides promising health benefits [39]. The study revealed a higher amount of omega-3 fatty acids, particularly DHA and EPA, found in hot smoked HDPS products, which are known to be effective in mitigating the onset of neurodegenerative complications in central nervous system neurons, cardiovascular disease progression, and arthritis [40-42]. PAHs are generally formed from incomplete combustion of organic matter such as wood materials while smoking and considered to be potential health hazards, in which BaP represents an effective genotoxic and carcinogenic to humans [43]. In considering food safety and public health, there need for further evaluation of the content of $\mathrm{BaP}$ in hot smoked HDPS. We determined the content of BaP in hot smoked HDPS and the result suggested that there was no detectable limit for BaP content $(<0.9 \mu \mathrm{g} / \mathrm{kg})$, indicating it to be acceptable and safe for human consumption $[43,44]$. A similar study found that BaP was not detected in commercial smoked sardine, silver carp, squid, or tuna [45].

\section{Conclusions}

Hot smoking $\left(70{ }^{\circ} \mathrm{C}\right)$ with selective Oak sawdust improved the sensorial and physicochemical attributes of HDPS. The inhibitory effects of HDPS on bacterial growth and TMAO content were observed in hot smoked HDPS fillet. Moreover, higher nutritional composition was obtained, of which beneficial polyunsaturated fatty acids, including DHA, EPA, and OLA, were remarkably high in our study. With all these preferential attributes in HDPS, it could become a product of premium quality to the consumer, with a shelf life that could be extended up to 32 days at $10^{\circ} \mathrm{C}$ storage conditions without concerning any quality loss. The present hot smoking process had no effects on PAHs accumulation, particularly BaP in HDPS fillets, indicating a safer food item for consumers. It is believed that this processing technique has great feasibility to preserve food products with both nutritional and functional characteristics in the future, particularly, for the pacific saury Cololabis saira.

Author Contributions: Conceptualization, J.-S.C., J.-S.K. and J.H.S.; methodology, J.-S.C. and J.H.S.; software, M.A.B., J.-S.C. and M.M.; validation, J.H.S. and J.-S.C.; formal analysis, N.E.W., M.A.B. and M.M.; investigation, N.E.W. and J.-S.C.; resources, N.E.W. and J.-S.C.; data curation, M.M. and J.-S.C.; writing—original draft preparation, M.A.B. and N.E.W.; writing - review and editing, M.M. and J.-S.C.; visualization, M.M.; supervision, J.-S.C.; project administration, J.-S.C., J.-S.K. and J.H.S.; funding acquisition, J.-S.C., J.-S.K. and J.H.S. All authors have read and agreed to the published version of the manuscript.

Funding: This research was funded by the Ministry of Oceans and Fisheries, Republic of Korea, grant number PJT200885. 
Acknowledgments: We are grateful to Yeseul Park, Hari Kim, Jong-Hoe Jeon, and Sung-Joon Yoon for their excellent technical assistance throughout this work.

Conflicts of Interest: The authors declare no conflict of interest.

\section{References}

1. Mei, J.; Ma, X.; Xie, J. Review on Natural Preservatives for Extending Fish Shelf Life. Foods 2019, 8, 490. [CrossRef] [PubMed]

2. Hicks, D.T. Seafood Safety and Quality: The Consumer's Role. Foods 2016, 5, 71. [CrossRef] [PubMed]

3. Sallam, K.I.; Ahmed, A.M.; Elgazzar, M.M.; Eldaly, E.A. Chemical quality and sensory attributes of marinated Pacific saury (Cololabis saira) during vacuum-packaged storage at 4 C. Food Chem. 2007, 102, 1061-1070. [CrossRef]

4. Matsumiya, Y. Dynamics of the saury population in the pacific ocean off northern Japan. I. abundance index in number by size category and fishing ground. Nippon Suisan Gakk. 1976, 42, 277-286. [CrossRef]

5. Hua, C.; Li, F.; Zhu, Q.; Zhu, G.; Meng, L. Habitat suitability of Pacific saury (Cololabis saira) based on a yield-density model and weighted analysis. Fish. Res. 2020, 221, 105408. [CrossRef]

6. Jang, M.-S.; Park, H.-Y.; Byun, H.-S.; Park, J.-I.; Kim, Y.-K.; Yoon, N.-Y.; Nam, C.-S. The Nutrient Composition of Commercial Kwamegi Admixed with Functional Ingredients. Korean J. Food Preserv. 2010, 17, 519-525.

7. Bouriga, N.; Ben Ismail, H.; Gammoudi, M.; Faure, E.; Trabelsi, A. Effect of smoking-method on biochemical and microbiological quality of Nile tilapia (Oreochromis niloticus). Am. J. Food Technol. 2012, 7, 679-689.

8. Adeyeye, S.A.O. Smoking of fish: A critical review. J. Culin. Sci. Technol. 2019, 17, 559-575. [CrossRef]

9. Arvanitoyannis, I.S.; Kotsanopoulos, K.V. Smoking of Fish and Seafood: History, Methods and Effects on Physical, Nutritional and Microbiological Properties. Food Bioproc. Technol. 2012, 5, 831-853. [CrossRef]

10. Bienkiewicz, G.; Tokarczyk, G.; Czerniejewska-Surma, B.; Suryn, J. Changes in the EPA and DHA content and lipids quality parameters of rainbow trout (Oncorhynchus mykiss, Walbaum) and carp (Cyprinus carpio, L.) at individual stages of hot smoking. Heliyon 2019, 5, e02964. [CrossRef]

11. Fuentes, A.; Fernández-Segovia, I.; Barat, J.M.; Serra, J.A. Physicochemical characterization of some smoked and marinated fish products. J. Food Process. Pres. 2010, 34, 83-103. [CrossRef]

12. Sutikno, L.A.; Bashir, K.M.I.; Kim, H.; Park, Y.; Won, N.E.; An, J.H.; Jeon, J.-H.; Yoon, S.-J.; Park, S.-M.; Sohn, J.H. Improvement in Physicochemical, Microbial, and Sensory Properties of Common Squid (Todarodes pacificus Steenstrup) by Superheated Steam Roasting in Combination with Smoking Treatment. J. Food Qual. 2019, 2019, 8721725. [CrossRef]

13. Huang, X.-H.; Qi, L.-B.; Fu, B.-S.; Chen, Z.-H.; Zhang, Y.-Y.; Du, M.; Dong, X.-P.; Zhu, B.-W.; Qin, L. Flavor formation in different production steps during the processing of cold-smoked Spanish mackerel. Food Chem. 2019, 286, 241-249. [CrossRef] [PubMed]

14. Goulas, A.E.; Kontominas, M.G. Effect of salting and smoking-method on the keeping quality of chub mackerel (Scomber japonicus): Biochemical and sensory attributes. Food Chem. 2005, 93, 511-520. [CrossRef]

15. Erkan, N. The effect of thyme and garlic oil on the preservation of vacuum-packaged hot smoked rainbow trout (Oncorhynchus mykiss). Food Bioproc. Technol. 2012, 5, 1246-1254. [CrossRef]

16. Mohibbullah, M.; Won, N.E.; Jeon, J.H.; An, J.H.; Park, Y.; Kim, H.; Bashir, K.M.I.; Park, S.M.; Kim, Y.S.; Yoon, S.J. Effect of superheated steam roasting with hot smoking treatment on improving physicochemical properties of the adductor muscle of pen shell (Atrina pectinate). Food Sci. Nutr. 2018, 6, 1317-1327. [CrossRef]

17. Baten, M.A.; Won, N.E.; Mohibbullah, M.; Yoon, S.-J.; Hak Sohn, J.; Kim, J.-S.; Choi, J.-S. Effect of hot smoking treatment in improving Sensory and Physicochemical Properties of processed Japanese Spanish Mackerel Scomberomorus niphonius. Food Sci. Nutr. 2020, 8, 3957-3968. [CrossRef]

18. Bİlgİn, S.; Ertan, Ö.; İzci, L. Investigation on changes in the chemical composition of hot smoked Salmo trutta macrostigma, Dumeril 1858, stored different temperatures. J. FisheriesSciences.com 2007, 1, 68-80. [CrossRef]

19. Stołyhwo, A.; Kołodziejska, I.; Sikorski, Z.E. Long chain polyunsaturated fatty acids in smoked Atlantic mackerel and Baltic sprats. Food Chem. 2006, 94, 589-595. [CrossRef]

20. Koral, S.; Köse, S.; Tufan, B. The effect of storage temperature on the chemical and sensorial quality of hot smoked Atlantic bonito (Sarda sarda, Bloch, 1838) packed in aluminium foil. Turkish J. Fish. Aquat. Sci. 2010, 10, 439-443.

21. Tenyang, N.; Tiencheu, B.; Womeni, H.M. Effect of smoking and refrigeration on lipid oxidation of Clupea harengus: A fish commonly consumed in Cameroon. Food Sci. Nutr. 2018, 6, 464-473. [CrossRef] [PubMed] 
22. Lim, J. Hedonic scaling: A review of methods and theory. Food Qual. Prefer. 2011, 22, 733-747. [CrossRef]

23. Macagnano, A.; Careche, M.; Herrero, A.; Paolesse, R.; Martinelli, E.; Pennazza, G.; Carmona, P.; D'amico, A.; Di Natale, C. A model to predict fish quality from instrumental features. Sensors Actuators B Chem. 2005, 111, 293-298. [CrossRef]

24. Chen, Y.; Wu, S.; Pan, S. Effect of water-soluble chitosan in combination with glutathione on the quality of pen shell adductor muscles. Int. J. Biol. Macromol. 2015, 72, 1250-1253. [CrossRef]

25. Ganesan, P.; Benjakul, S. Effect of glucose treatment on texture and colour of pidan white during storage. Int. J. Food Sci. Technol. 2014, 51, 729-735. [CrossRef]

26. Oğuzhan Yildiz, P. Effect of essential oils and packaging on hot smoked rainbow trout during storage. J. Food Process. Preserv. 2015, 39, 806-815. [CrossRef]

27. Horwitz, W. Food composition; additives; natural contaminants. In Official Methods of Analysis of AOAC International, 17th ed.; Horwitz, W., Ed.; AOAC International: Rockville, MD, USA, 2000.

28. Ministry of Food and Drug Safety (MFDS). Food Code, Korean Foods Industry Association; Korean Foods Industry Association Press: Seoul, Korea, 2014.

29. Weichselbaum, E.; Coe, S.; Buttriss, J.; Stanner, S. Fish in the diet: A review. Nutr. Bull. 2013, 38, $128-177$. [CrossRef]

30. Cho, S.-Y.; Endo, Y.; Fujimoto, K.; Kaneda, T. Oxidative Deterioration of Lipids in Salted and Dried. Nippon Suisan Gakk. 1989, 55, 541-544. [CrossRef]

31. Secci, G.; Parisi, G. From farm to fork: Lipid oxidation in fish products. A review. Ital. J. Anim. Sci. 2016, 15, 124-136. [CrossRef]

32. Dillon, R.; Patel, T.R.; Martin, A.M. Microbiological control for fish smoking operations. In Fisheries Processing; Springer: Berlin/Heidelberg, Germany, 1994; pp. 51-81.

33. Oz, A.T.; Ulukanli, Z.; Bozok, F.; Baktemur, G. The Postharvest Quality, Sensory and Shelf Life of A garicus Bisporus in Active Map. J. Food Process. Preserv. 2015, 39, 100-106. [CrossRef]

34. Nollet, L.M.L.; Toldrá, F. Handbook of Seafood and Seafood Products Analysis; CRC Press: Boca Raton, FL, USA, 2009.

35. Zzaman, W.; Bhat, R.; Yang, T.A.; Easa, A.M. Influences of superheated steam roasting on changes in sugar, amino acid and flavour active components of cocoa bean (Theobroma cacao). J. Sci. Food Agric. 2017, 97, 4429-4437. [CrossRef] [PubMed]

36. Guillén, M.D.; Errecalde, M.C. Volatile components of raw and smoked black bream (Brama raii) and rainbow trout (Oncorhynchus mykiss) studied by means of solid phase microextraction and gas chromatography/mass spectrometry. J. Sci. Food Agric. 2002, 82, 945-952. [CrossRef]

37. Anastasio, A.; Marrone, R.; Chirollo, C.; Smaldone, G.; Attouchi, M.; Adamo, P.; Sadok, S.; Pepe, T. Swordfish steaks vacuum-packed with Rosmarinus officinalis. Ital. J. Food Sci. 2014, 26, 390-397.

38. Menon, V. Seafood Processing: Adding Value through Quick Freezing, Retortable Packaging, and Cook-Chilling; CRC Press: Boca Raton, FL, USA, 2005; pp. 1-486.

39. Monllor, P.; Romero, G.; Atzori, A.S.; Sandoval-Castro, C.A.; Ayala-Burgos, A.J.; Roca, A.; Sendra, E.; Díaz, J.R. Composition, Mineral and Fatty Acid Profiles of Milk from Goats Fed with Different Proportions of Broccoli and Artichoke Plant By-Products. Foods 2020, 9, 700. [CrossRef]

40. Shahidi, F.; Ambigaipalan, P. Omega-3 Polyunsaturated Fatty Acids and Their Health Benefits. Annu. Rev. Food Sci. Technol. 2018, 9, 345-381. [CrossRef]

41. Mohibbullah, M.; Choi, J.S.; Bhuiyan, M.M.H.; Haque, M.N.; Rahman, M.K.; Moon, I.S.; Hong, Y.K. The Red Alga Gracilariopsis chorda and Its Active Constituent Arachidonic Acid Promote Spine Dynamics via Dendritic Filopodia and Potentiate Functional Synaptic Plasticity in Hippocampal Neurons. J. Med. Food 2018, 21, 481-488. [CrossRef]

42. Mohibbullah, M.; Hannan, M.A.; Choi, J.Y.; Bhuiyan, M.M.; Hong, Y.K.; Choi, J.S.; Choi, I.S.; Moon, I.S. The Edible Marine Alga Gracilariopsis chorda Alleviates Hypoxia/Reoxygenation-Induced Oxidative Stress in Cultured Hippocampal Neurons. J. Med. Food 2015, 18, 960-971. [CrossRef]

43. Hokkanen, M.; Luhtasela, U.; Kostamo, P.; Ritvanen, T.; Peltonen, K.; Jestoi, M. Critical Effects of Smoking Parameters on the Levels of Polycyclic Aromatic Hydrocarbons in Traditionally Smoked Fish and Meat Products in Finland. J. Chem. 2018, 2018, 2160958. [CrossRef] 
44. Stołyhwo, A.; Sikorski, Z.E. Polycyclic aromatic hydrocarbons in smoked fish-A critical review. Food Chem. 2005, 91, 303-311. [CrossRef]

45. Kannappan, S.; Jasmine, G.I.; Jeyachandran, P.; Selvi, A.T. Polyaromatic hydrocarbons in processed fishery products. J. Food Sci. Technol. 2000, 37, 596-601.

(C) 2020 by the authors. Licensee MDPI, Basel, Switzerland. This article is an open access article distributed under the terms and conditions of the Creative Commons Attribution (CC BY) license (http://creativecommons.org/licenses/by/4.0/). 